\title{
Uma base comum na escola: análise do projeto educativo da Base Nacional Comum Curricular
}

Fabiana Alvarenga Filipe ${ }^{a}$ Dayane dos Santos Silva ${ }^{b}$ Áurea de Carvalho Costa c

\section{Resumo}

O objetivo desse artigo foi analisar o projeto educativo proposto como fundamento da Base Nacional Comum Curricular (BNCC). Realizamos uma pesquisa qualitativa e documental da versão final da BNCC, de abril de 2017, homologada em 20 de dezembro de 2017 pelo Conselho Nacional de Educação. Identificamos que a BNCC se fundamenta num projeto educativo de formação para a empregabilidade, com a centralidade das competências, a partir de um modelo de Ensino direcionado, prescritivo e vinculado a um modelo de avaliação eficientista, inspirado nas teorias comportamentais, e concluímos que as proposições da BNCC se distanciam de um projeto educativo que vise a uma formação crítica e emancipatória, ao formar para o trabalho segundo as demandas neoliberais.

Palavras-chave: Base Nacional Comum Curricular. Concepções de Currículo. Projeto Educativo Neoliberal.

\section{Introdução}

A organização do trabalho, no capitalismo, estrutura-se sob o regime de acumulação privada de capital pela classe detentora dos meios de produção, a partir da exploração do trabalho da classe produtora, que se acirra a cada crise, demandando novas estratégias para a intensificação da exploração, pois somente o trabalho humano cria valor novo (MARX, 1998). Tais estratégias se desenvolvem sob o suporte do Estado burguês, o qual garante as condições favoráveis à exploração, no âmbito econômico e das instituições irradiadoras de consensos, que conformam a sociedade a esse status quo.

\footnotetext{
a Universidade Estadual Paulista "Júlio de Mesquita Filho", Rio Claro, SP, Brasil.

b Universidade Estadual Paulista "Júlio de Mesquita Filho", Rio Claro, SP, Brasil.

c Universidade Estadual Paulista "Júlio de Mesquita Filho", Rio Claro, SP, Brasil.
} 
Nesse momento do modo de produção capitalista, institui-se a estratégia políticoeconômica neoliberal, que serve à preservação dos interesses mercadológicos numa conjuntura de crise metabólica do capitalismo, como parte da solução para o processo de perdas de lucratividade. Edifica-se um novo modelo de Estado, que deverá redirecionar os investimentos do erário público para salvaguardar os interesses do capital e produzir o consenso de que ele se preocupa com uma aplicação mais racional e eficiente daquele erário.

Uma vez inserida e subordinada ao modo de produção capitalista, a escola vive uma contradição: por um lado, reproduz a contradição fundamental do capitalismo - a divisão da sociedade em classes antagônicas - nos seus objetivos específicos de prover essa sociedade de um projeto educativo influenciado pelos interesses burgueses de formar os indivíduos com competências para disputar uma vaga no mercado de trabalho e se submeter à intensificação e à precarização do trabalho; por outro, pode proporcionar os elementos necessários à compreensão crítica dessa realidade e sua transformação.

A formação escolar capitalista, aparentemente, possibilita a manutenção do poder da classe dominante sobre a trabalhadora, a partir da formação desta para as exigências do mundo do trabalho, mas a classe trabalhadora não recebe tal projeto educativo sem resistências e apropriações próprias dos conteúdos do Ensino, o que torna a escola dialética (GRAMSCI, 1982). A escola capitalista é um espaço de disputas entre as classes sociais, pela hegemonia sobre o conhecimento, pois não alcança o total controle sobre o que os indivíduos apreendem e o impacto deste no avanço da consciência crítica. Porém, os arautos desse modelo de escolarização insistem em desenvolver dispositivos legais de controle de gestores, professores, bem como das avaliações e do currículo.

Nessa disputa pelo saber sistematizado, coloca-se a questão relacionada à hegemonia estatal sobre as escolhas relativas ao "quanto", "quando", "o que" e "como" ensinar, traduzindo-se em disputas referentes ao currículo, as quais se apresentam concretamente nas formas de seleção, organização e seriação dos conteúdos do Ensino, bem como das práticas pedagógicas requeridas para a implantação de tais decisões. Neste artigo discutimos quais são os interesses atendidos a partir das escolhas do que se ensina na escola constantes na Base Nacional Comum Curricular (BNCC).

No contexto educacional, as decisões sobre a formação escolar e a escolha dos conteúdos do currículo são técnicas e políticas, pois ele é "[...] a própria escola em pleno funcionamento [...]", a partir da sua "[...] atividade nuclear que é a de 
propiciar aos alunos o ingresso na cultura letrada assegurando-lhes a aquisição dos instrumentos de acesso ao saber elaborado" (SAVIANI, 2016, p. 55,57).

Tais decisões traduzem-se em políticas educacionais peculiares ao modo de produção da sociedade capitalista, no âmbito da estratégia político-econômica mais ampla, neoliberal. Por isso realizamos a análise documental da política da BNCC para apreender o projeto educativo que perpassa as compreensões de currículo presentes na BNCC, a partir das problematizações: que projeto educativo perpassa a BNCC? Que aspectos das teorias de currículo estão presentes nesse documento?

A BNCC teve três versões: a de junho de 2015, disponibilizada de setembro até março de 2016 para críticas e sugestões da comunidade; a segunda disponibilizada em maio de 2016, e a terceira, disponibilizada em abril de 2017 e homologada em 20 de dezembro, após tramitar pelo Conselho Nacional de Educação.

Empreendemos um estudo qualitativo do corpus documental da terceira versão da BNCC, estruturado a partir dos itens de Introdução, Estrutura da BNCC, Etapa da Educação Infantil (direitos de aprendizagens e de desenvolvimento em campos de aprendizagem); Etapa do Ensino Fundamental (áreas de conhecimento e competências específicas de área, componentes curriculares e competências específicas de componente); e a Etapa do Ensino Médio (áreas do conhecimento e competências específicas de área).

Tendo em vista a influência desse documento no processo de seleção, de organização e de avaliação do currículo, analisamos a Introdução composta pelos subitens de apresentação e os marcos legais que embasam a BNCC, bem como seus fundamentos pedagógicos, o pacto Inter federativo e sua implementação.

Estruturamos o artigo, em três seções: inicialmente, apresentamos as concepções de currículo, em diferentes momentos da história da Educação brasileira; depois, analisamos o corpus documental e, por fim, apresentamos nossa síntese na forma de considerações.

\section{As teorias de currículo no século XX: apresentação das concepções em disputa}

Diante do desenvolvimento industrial nos Estados Unidos da América (EUA) e da demanda de trabalhadores para ocupar esse espaço na década de 1990, os currículos tornaram-se objeto de disputa entre as classes sociais, o direcionamento da formação dessa mão de obra e as vinculações entre Educação e demandas do capital. 
A partir da ampliação do Ensino nos EUA, surgiram movimentos questionadores dos conteúdos do Ensino nessas escolas e, na década de 1920, surgiram propostas tributárias do "eficientismo social" ou do "progressivismo". Sob inspiração da organização científica do trabalho, de Taylor, em 1918, Jonh Franklin Bobbitt publicou o livro "The curriculum", no qual a escola seria "[...] capaz de especificar precisamente quais resultados pretendia obter, que pudesse estabelecer métodos para obtê-los de forma precisa e formas de mensuração que permitissem saber com precisão se eles foram realmente alcançados" (SILVA, 2013, p. 23). Evidenciava-se um projeto em que a Educação escolar tinha o papel de formar o aluno para uma vida adulta de atuação no mercado de trabalho, mas sem preocupação explícita com a seleção dos conteúdos e das práticas pedagógicas.

Concomitantemente a essa concepção, desenvolveu-se o "progressivismo" representado pelo pensamento educacional de Dewey, cuja tendência influenciou autores como Kilpatrick, que desenvolveu o "Método de Projetos", cuja ideia central era "[...] de que o conhecimento deve ser buscado pelos alunos a partir de necessidades de sua vida real, opondo-se aos currículos preestabelecidos nos quais o conhecimento é organizado numa sequência lógica e temporal" (DUARTE, 2010, p. 41). Tal concepção de currículo influenciou o desenvolvimento do "Movimento da Escola Nova" no Brasil, na década de 1930, sob a liderança de Anísio Teixeira e de Fernando de Azevedo (LOPES; MACEDO, 2011).

Apesar da força do Movimento escolanovista, na década de 1930, a proposta que prevaleceu no período de 1950 até o início dos anos 1970, no Brasil, foi desenvolvida por Ralph Tyler, que articulou as "abordagens técnicas e eficientistas com pensamento progressivo" (LOPES; MACEDO, 2011, p. 25). Tal articulação deu-se a partir da "[...] definição de metas/objetivos e de formas de verificação de sua consecução, secundada pela proposição de experiências que facilitem seu domínio" (LOPES; MACEDO, 2011, p. 44).

Alguns desdobramentos da compreensão de Tyler ainda se fazem presentes nos dias de hoje, a partir de uma ressignificação dos conceitos desenvolvidos por ele como a estreita relação entre currículo e avaliação, bem como a influência das Teorias da Competência, cujas matrizes teóricas e metodológicas se voltam para a proposição de orientações educacionais e para a necessidade de se estabelecer critérios objetivos e científicos para as atividades escolares, como a Taxonomia dos Objetivos Educacionais de Benjamin S. Bloom, em 1956. Essa taxonomia compreende três domínios: cognitivo, afetivo e psicomotor, cuja base foi “[...] um sistema de classificação de objetivos, de vez que estes constituem a base do 
planejamento do currículo e da avaliação e representam o ponto de partida de muitas de nossas pesquisas educacionais" (BLOOM, 1973, p.4).

Nos anos 1960, as críticas à concepção comportamentalista motivaram a proposição de novos fundamentos para se conceber o currículo, propugnada pelos pensadores de correntes como a "Nova Sociologia da Educação" (NSE), na Inglaterra (Michael Young) e a "Sociologia do Currículo", nos EUA(Michael W. Apple) (MACEDO, 2012; SILVA, 2013).

No cenário nacional, o processo de redemocratização, a partir de 1984, possibilitou a retomada das proposições de autores críticos das concepções tecnicistas da Educação, como Paulo Freire, bem como a emergência da "Pedagogia Históricocrítica", (Demerval Saviani) e a "Pedagogia Crítico-social dos conteúdos" (José Carlos Libâneo) (LOPES; MACEDO, 2011).

As críticas se dirigiam ao foco exacerbado na eficiência, na objetividade, na neutralidade e na técnica ao propor a seleção e a organização do conhecimento a ser ensinado, mas não se restringiram às proposições críticas de currículo, uma vez que eram também questionadas do ponto de vista das perspectivas influenciadas pelos referenciais teóricos pós-críticos (SILVA, 2013).

Diante desse debate, surge a hipótese de que o currículo é um espaço de criação e de resistência perante as demandas hegemônicas da escola capitalista, mediante a demanda econômica de formação para a empregabilidade. Tais tensões e contradições ultrapassam o currículo e atingem o cotidiano da sala de aula, desde a construção dos planos de aulas, que deve ser objeto de estudo próprio, até a elaboração das políticas curriculares nacionais que destacamos.

\section{Os princípios da BNCC}

A BNCC é uma política nacional curricular que "[...] constitui-se enquanto um documento normativo que seleciona e organiza os conhecimentos a serem ensinados ao longo dos níveis e modalidades da Educação básica no Brasil" (BRASIL, 2018, p. 7).

Tal documento foi assinado pelo ministro da Educação, José Mendonça Filho, com mandato no período de maio de 2016 a abril de 2018 - em parceria com o Conselho Nacional de Secretários de Educação - Consed - e com a União Nacional dos Dirigentes Municipais de Educação - Undim - que o saúda como uma inovação na Educação, ao afirmar que "[...] o Brasil inicia uma nova era 
na educação brasileira e se alinha aos melhores e mais qualificados sistemas educacionais do mundo" (BRASIL, 2018, p. 5) e apontar como virtudes da proposta a pluralidade, a modernização, a democratização do conhecimento e a potência do documento para a homogeneização das redes de Ensino:

\begin{abstract}
A BNCC é um documento plural, contemporâneo, e estabelece com clareza o conjunto de aprendizagens essenciais e indispensáveis a que todos os estudantes, crianças, jovens e adultos, têm direito. Com ela, redes de ensino e instituições escolares públicas e particulares passam a ter uma referência nacional obrigatória para a elaboração ou adequação de seus currículos e propostas pedagógicas. Essa referência é o ponto ao qual se quer chegar em cada etapa da Educação Básica, enquanto os currículos traçam o caminho até lá (BRASIL, 2018, p. 5).
\end{abstract}

O conjunto de aprendizagens essenciais e indispensáveis, referido no texto, reproduz o discurso proposto na "Declaração Mundial sobre Educação para Todos: Satisfação das Necessidades Básicas de Aprendizagem", que é resultado da Conferência Mundial da Educação para Todos, realizada em Jomtien, na Tailândia, em 1990. Essas "necessidades essenciais", de acordo com a Declaração,

[...] compreendem tanto os instrumentos essenciais para a aprendizagem (como a leitura e a escrita, a expressão oral, o cálculo, a solução de problemas), quanto os conteúdos básicos da aprendizagem (como conhecimentos, habilidades, valores e atitudes), necessários para que os seres humanos possam sobreviver, desenvolver plenamente suas potencialidades, viver e trabalhar com dignidade, participar plenamente do desenvolvimento, melhorar a qualidade de vida, tomar decisões fundamentadas e continuar aprendendo (UNESCO, 1990, art.1, 1).

Como podemos observar, a ideia das "Necessidades Básicas de Aprendizagem" visa a disponibilizar à classe trabalhadora um mínimo de conhecimentos, para que possa se adaptar à fase atual do capitalismo. Entretanto, ao mesmo tempo em que promete aos alunos aprendizagens que lhes são de direito, ao delimitar um rol de aprendizagens, restringe o direito ao conhecimento em sua globalidade. Enfim, a proposta pedagógica para as classes trabalhadoras oferece o acesso ao básico, definido pelos organismos internacionais promotores da conferência como necessário para formar mão de obra nos países subdesenvolvidos e em desenvolvimento, e não ao desenvolvimento das máximas potencialidades humanas, 
cujos conteúdos são reservados às escolas das elites. Tampouco há diretrizes para a formação de cidadãos para a compreensão da realidade local e regional e suas peculiaridades, como, por exemplo, do Brasil e da América Latina nas esferas econômica, social, política, histórica e cultural. O referente do ministro para apresentar a BNCC como proposta de excelência são os parâmetros de qualidade em Educação impostos pelos grandes centros do capitalismo. Esse discurso "[...] a favor das NEBA é revestido de um apelo sedutor ao desenvolvimento da autonomia do indivíduo, ao autodidatismo e ao lema das "pedagogias do aprender a aprender" (BULHÕES, 2016, p. 23).

Contudo, o discurso da formação autônoma e autodidata, bem como do protagonismo juvenil na escolha dos itinerários formativos serve como argumento demagógico para justificar uma formação escolar a distância, modular, submetida aos requisitos da empregabilidade, entendida como capacidade de competir no mercado por um emprego, a partir dos atributos desenvolvidos por cada trabalhador. Assim, "a BNCC é apresentada como uma política para todos, e a exclusão que ela potencialmente promove é decorrência da ação individual daqueles que são excluídos" (MACEDO, 2017, p. 517).

Tal proposta educativa é congruente com as demandas do capital na conjuntura neoliberal de compressão da estrutura dos sistemas públicos de Ensino para abertura de nichos de mercado para o ramo de negócios da Educação privada (CUNHA, 2007), atribuindo aos indivíduos a responsabilidade sobre seu percurso formativo, o que se revela como atuação mínima do Estado, no campo da Educação, tanto em termos de provimento e de máxima quanto em termos de regulação, como se constata nos documentos oficiais como o Plano de Desenvolvimento da Educação (PDE).

Para tanto, fez-se necessário um currículo fundamentado na pedagogia das competências e no multiculturalismo como expressão pedagógica do respeito às diferenças, homogeneizando as diferentes formas de conhecimento, apagando as condições de sua produção, com diferentes níveis de complexidade: “[...] estratégia contida na proposta das NEBA de se utilizar do multiculturalismo para justificar organizações de Ensino cada vez mais aligeiradas para a classe trabalhadora que atinge seu ápice com as Diretrizes Curriculares Nacionais Gerais para a Educação Básica" (BULHÕES, 2016, p. 26).

Ao se reduzir a Educação a um processo de aquisição de competências e de habilidades, por meio de currículos multiculturalistas, tal proposta abjura do objetivo de desenvolvimento das funções psíquicas por meio da aprendizagem 
do conhecimento científico, artístico e filosófico, pois a ênfase passa a ser no mínimo necessário para que os cidadãos concluam seus estudos dotados de informações, instruções e habilidades, que se constituem numa das dimensões do conhecimento, pois o Estado se compromete em "[...] garantir ao aluno o acesso ao básico, $[\ldots]$ " faz com que haja remissão da "[...] sociedade de ter promovido a desigualdade social que o vitimou, abrindo-lhe as portas do sucesso, agora, na dependência de seu empenho", ou seja, daqui para a frente, depende dele (FREITAS, 2014, p. 1090-1091).

Institui-se uma visão de Educação como serviço a ser oferecido pelo Estado em níveis de suficiência, não de excelência, na perspectiva monetarista.

Essa visão economicista, presente em várias políticas, tem apenas como referência critérios econômicos, como eficiência e redução de gastos, e advoga primordialmente que a educação se concentre na preparação de mão de obra para o mundo do trabalho, em função do desenvolvimento econômico (SANTOS, 2017, p. 12).

Hoje, a BNCC é a referência nacional obrigatória para adequação dos currículos da Educação Básica com função técnica/instrumental homogeneizante, subsumindo as especificidades locais e regionais e impondo os objetivos e as temáticas privilegiadas para o alcance do desenvolvimento das "dez competências gerais" da Educação Básica nos alunos, de todos os níveis e modalidades de Ensino. Tendo o pressuposto de que a competência se define como "[...] a mobilização de conhecimentos [...], habilidades [...], atitudes e valores para resolver demandas complexas da vida cotidiana, do pleno exercício da cidadania e do mundo do trabalho" (BRASIL, 2018, p. 8), numa perspectiva pragmática.

Os objetivos proclamados para a escolha dessas dez competências gerais guardam uma contradição: prometem preparar os alunos criticamente para a construção de uma sociedade justa, democrática e inclusiva, com atividades diversificadas, mas capitulam ao projeto ideológico de desenvolvimento da capacidade de adaptação dos sujeitos às práticas sociais de amenização/gerenciamento dos conflitos, para a perpetuação do status quo. Além disso, fomentam um desenvolvimento de personalidades individualistas flexíveis, resilientes e competitivas, ao mesmo tempo que autônomas e determinadas.

Isso se revela concretamente ao compararmos os verbos expressos nos objetivos das competências gerais da BNCC (OCGB) e os presentes na Taxonomia dos Objetivos Educacionais de Bloom (Toeb) (1956). Cada domínio é formado por 
categorias organizadas em níveis de hierarquia e complexidade crescentes - do mais simples ao mais complexo - que são: no domínio cognitivo, conhecimento, compreensão, aplicação, análise, síntese e avaliação; no afetivo, recepção, resposta, valorização, organização e internalização de valores; e no psicomotor, habilidades que possuem como foco a manipulação de objetos ou de materiais. De maneira que há um conjunto de verbos vinculado a cada uma dessas categorias e que orientam a ação a ser desenvolvida (BLOOM, 1973; FERRAZ; BELHOT, 2010).

Assim, buscamos identificar os verbos utilizados nos OCGB e comparamos com os verbos presentes em cada categoria dos domínios da Toeb. Em seguida, verificamos a categoria e o domínio que os verbos estavam relacionados, e observou-se que esses estão associados às categorias referentes ao domínio afetivo e cognitivo, prevalecendo este último, e categorias de níveis de menor complexidade (Quadro 1).

Quadro 1 - Associação dos verbos dos objetivos das Competências gerais da BNCC e dos verbos presentes nas categorias dos domínios da Taxonomia dos objetivos educacionais

\begin{tabular}{|c|c|c|c|}
\hline \multicolumn{2}{|c|}{ Competências gerais da BNCC } & \multicolumn{2}{|c|}{$\begin{array}{l}\text { Domínios e categorias da } \\
\text { Taxonomia de Bloom }\end{array}$} \\
\hline Competências & $\begin{array}{l}\text { Verbos em comum com as das } \\
\text { categorias da Taxonomia de Bloom }\end{array}$ & Cognitivo & Afetivo \\
\hline \multirow{3}{*}{1} & Utilizar & $3^{\circ *}$ Aplicação & - \\
\hline & Explicar & $2^{\circ}$ Compreensão & - \\
\hline & Valorizar & - & $3^{\circ}$ Valorização \\
\hline 2 & Investigar & $4^{\circ}$ Análise & - \\
\hline 3 & Valorizar & - & $3^{\circ}$ Valorização \\
\hline 4 & Utilizar & $3^{\circ}$ Aplicação & - \\
\hline \multirow{3}{*}{5} & Utilizar & $3^{\circ}$ Aplicação & - \\
\hline & Compreender & $2^{\circ}$ Compreensão & - \\
\hline & Criar & $5^{\circ}$ Síntese & - \\
\hline 6 & Valorizar & & $3^{\circ}$ Valorização \\
\hline \multirow{2}{*}{7} & Formular & $5^{\circ}$ Síntese & - \\
\hline & Defender & $2^{\circ}$ Compreensão & - \\
\hline \multirow{2}{*}{8} & Conhecer & $1^{\circ}$ Conhecimento & - \\
\hline & Apreciar & $6^{\circ}$ Avaliação & - \\
\hline 9 & Exercitar & $3^{\circ}$ Aplicação & - \\
\hline 10 & Agir & $3^{\circ}$ Aplicação & - \\
\hline
\end{tabular}

*Numerais ordinais representando a complexidade crescente das categorias dos domínios da Taxonomia de Bloom

Fonte: Elaboração das autoras (2019) a partir de Bloom (1973), Ferraz e Belhot (2010) 
A análise do Quadro 1 demonstra que as OCGB se fundamentam no mesmo eficientismo e na preocupação com a mudança de comportamentos visíveis, o que influenciou o currículo na década de 1960 e 1970, no Brasil. Os verbos utilizados nos objetivos educacionais designam ações de diferentes níveis de complexidade, desde as requeridas nas ações práticas, atitudinais, como a de utilizar, investigar, exercitar e agir, passando por aquelas que designam ações mentais, expressas pelos verbos explicar, compreender, formular e conhecer, até as que demandam o exercício do julgamento fundamentado, como valorizar, defender, criar e apreciar.

Ao se apresentarem os marcos legais que fundamentam as proposições das BNCC constatamos o apelo ao artigo constitucional n $n^{\circ} 205$ : “[...] a Educação, direito de todos e dever do Estado e da família, será promovida e incentivada com a colaboração da sociedade, visando ao pleno desenvolvimento da pessoa, seu preparo para o exercício da cidadania e sua qualificação para o trabalho"; o artigo 210: "Serão fixados conteúdos mínimos para o ensino fundamental, de maneira a assegurar formação básica comum e respeito aos valores culturais e artísticos, nacionais e regionais" (BRASIL, 1988) e o inciso IV, do artigo $9^{\circ}$, da Lei de Diretrizes e Bases da Educação Nacional (LDBEN), que prevê que é de responsabilidade da União o estabelecimento de competências e diretrizes que devem nortear os currículos, assegurando uma formação básica comum para a Educação Infantil e para o Ensino Médio.

$\mathrm{O}$ texto da BNCC afirma que, nessa legislação, se enfatizam dois aspectos: "O primeiro [...] estabelece a relação entre o que é básico-comum e o que é diverso em matéria curricular: as competências e diretrizes são comuns, os currículos são diversos. O segundo se refere ao foco do currículo" (BRASIL, 2018, p. 11). Para diferenciar o que é comum do que é diverso, o documento apoia-se nos artigos $9^{\circ}$ e 26 da LDBEN, trazendo a ideia de que haverá uma parte diversificada, que respeitará as características regionais e locais.

A garantia da "base-comum" foi contemplada nos Parâmetros Curriculares Nacionais (PCN), mas estes não se impuseram como diretrizes obrigatórias. Contrariamente, a BNCC é "[...] uma referência nacional obrigatória para a elaboração ou adequação de seus currículos e propostas pedagógicas" (BRASIL, 2018, p. 5).

Trata-se de um retrocesso, tendo em vista que os PCN surgiram como uma superação dos guias curriculares, impostos durante a ditadura militar e das propostas curriculares, ao romper com a ideia de conteúdos dispostos, de forma 
a propor uma seleção e uma sequência, proporcionando aos professores maior autonomia, indicando-lhes objetivos mais gerais. Já na BNCC, os objetivos são apresentados de forma detalhada, ano a ano. As áreas de conhecimento como as de linguagens e códigos são extraídas das Diretrizes Curriculares Nacionais e a base operacionaliza essa intencionalidade, numa perspectiva de controle rígido sobre o que o professor ensina na sala de aula, que parece responder aos anseios de setores da sociedade ligados ao movimento Escola sem partido e os fundamentalistas cristãos (CARVALHO; POLIZEL; MAIO, 2016).

Entretanto, a BNCC, assim como os PCN, estimula o Ensino dos conteúdos a serem avaliados por meio do sistema de avaliação nacional - o qual, por sua vez, se inspira em avaliações de rendimento escolar dos organismos internacionais, como o Programa Internacional de Avaliação de Estudantes - PISA (proposto pela Organização para a Cooperação e Desenvolvimento Econômico, doravante, OCDE) - estimulando a competição entre as escolas, pois nele se sugere a classificação das escolas, a partir de "[...] seu desempenho, com a justificativa de que isso facilitaria aos pais a escolha do estabelecimento escolar para seus filhos. [...] ao ranquear as escolas, se introduziria a competição entre elas, aumentando a produtividade do sistema educacional" (SANTOS; DINIZ-PEREIRA, 2016, p. 285). Observa-se o desenvolvimento de políticas curriculares e de avaliação que "[...] têm em seu escopo o controle e a responsabilização advindos do accountability e justificados pela ideia de melhoria da qualidade da educação" (FRANGELLA; MENDES, 2018, p. 310).

A Lei n ${ }^{\circ}$ 13.005/2014, que institui o Plano Nacional de Educação (PNE), também é marco legal evocado na BNCC, especialmente a estratégia 7.1: “[...] diretrizes pedagógicas para a educação básica e a base nacional comum dos currículos, com direitos e objetivos de aprendizagem e desenvolvimento [...] respeitadas as diversidades regional, estadual e local” integrante da Meta 7, do PNE: “[...] fomentar a qualidade da Educação Básica em todas as etapas e modalidades, com melhoria do fluxo escolar e da aprendizagem [...]" (BRASIL, 2014, p. 4). Além disso, apresenta três quadros com os índices a serem atingidos para os anos iniciais e finais do Ensino Fundamental e do Ensino Médio, com periodicidade bienal nos anos de 2015, 2017, 2019 e 2021.

A BNCC é um desdobramento do PNE, em que já constam os direitos e os objetivos de aprendizagem e de desenvolvimento a serem submetidos para a aferição da qualidade educacional, vinculada aos índices quantitativos. Ao analisarmos tais marcos legais, observamos que, para além de servirem à justificação da legalidade da BNCC, são peças jurídicas que vêm consolidando, desde a década de 1990, 
uma tendência à redução do direito à Educação ao direito à aprendizagem, cujo currículo é instrumento para o cumprimento de tais direitos:

O direito à formação ampla e contextualizada que todo ser humano deve ter é reduzido ao direito de aprender o "básico" expresso nas matrizes de referência dos exames nacionais, assumido ali como o domínio que é considerado "adequado" para uma dada série escolar nas disciplinas avaliadas - não por acaso as que estão mais diretamente ligadas às necessidades dos processos produtivos: leitura, matemática e ciências. Convém enfatizar que são as matrizes de referência dos exames e não o currículo prescrito, a base nacional comum, que definem o que será considerado como "básico" (FREITAS, 2014, p. 1090, grifos do autor).

O fundamento pedagógico do documento em análise é, de fato, a pedagogia das competências, cujo limite é preparar os alunos tão somente " [...] para resolver demandas complexas da vida cotidiana, do pleno exercício da cidadania e do mundo do trabalho [...]" (BRASIL, 2018, p. 13), coerentemente com a LDBEN.

A adoção acrítica da pedagogia das competências, por parte do Estado, justifica-se enquanto consenso mundial, e tem orientado pedagogicamente redes educacionais da maioria dos municípios e dos estados brasileiros, bem como na Austrália, em Portugal, na França, na Polônia, nos Estados Unidos da América, nos Chile e no Peru. Mesmo porque, o domínio delas é condição básica para um bom posicionamento no ranking internacional da Educação que é sistematizado a partir dos resultados do programa internacional de avaliação do rendimento escolar, o PISA, enfoque adotado nas avaliações internacionais da OCDE e também “[...] da Organização das Nações Unidas para a Educação, a Ciência e a Cultura [...], que instituiu o Laboratório Latino-americano de Avaliação da Qualidade da Educação para a América Latina [...]" (BRASIL, 2018, p. 13).

Mundialmente, tem sido construído um consenso de que os países participantes do PISA teriam os sistemas mais qualificados, portanto, alinhar-se a eles significaria adotar uma concepção de qualidade educacional superior, o que, na verdade, é uma rendição às diretrizes internacionais para a Educação nacional:

Por meio da indicação clara do que os alunos devem "saber" (considerando a constituição de conhecimentos, habilidades, atitudes e valores) e, sobretudo, do que devem "saber fazer" (considerando a mobilização desses conhecimentos, habilidades, atitudes e valores 
para resolver demandas complexas da vida cotidiana, do pleno exercício da cidadania e do mundo do trabalho), a explicitação das competências oferece referências para o fortalecimento de ações que assegurem as aprendizagens essenciais definidas na BNCC. (BRASIL, 2018, p. 13, grifos nossos).

O documento abstrai as críticas e os limites da teoria das competências, impondo-se como uma teoria da aprendizagem unívoca e consensual, uma decisão de natureza técnica, quando, na verdade, trata-se de decisão política, vinculada à demanda do capital por formação de trabalhadores com perfil para a atuação resiliente num mercado de trabalho escasso de empregos e de direitos laborais.

Um aspecto progressivo a destacar é que o compromisso com a Educação integral não se refere apenas à duração da jornada escolar, mas “[...] à construção intencional de processos educativos que promovam aprendizagens sintonizadas com as necessidades, as possibilidades e os interesses dos estudantes e, também, com os desafios da sociedade contemporânea" (BRASIL, 2018, p. 14). Esses desafios dizem respeito às competências para sobreviver numa sociedade que vive uma das piores crises de falta de trabalho para a maioria da população mundial devido às reestruturações produtivas na conjuntura posterior à crise mundial da década de 1970, mas que é difundido como realidade irrefutável e irreversível, restando à escola o papel de preparar os cidadãos para serem, antes, proativos, pois:

No novo cenário mundial, reconhecer-se em seu contexto histórico e cultural, comunicar-se, ser criativo, analítico-crítico, participativo, aberto ao novo, colaborativo, resiliente, produtivo e responsável requer muito mais do que o acúmulo de informações. [...] o desenvolvimento de competências para aprender a aprender, saber lidar com a informação cada vez mais disponível, atuar com discernimento e responsabilidade nos contextos das culturas digitais, aplicar conhecimentos para resolver problemas, ter autonomia para tomar decisões, ser proativo para identificar os dados de uma situação e buscar soluções, conviver e aprender com as diferenças e as diversidades (BRASIL, 2018, p. 14).

Há uma focalização na demanda social de uma escolarização promotora de igualdade, diversidade e equidade, com respeito à diversidade cultural, numa realidade de desigualdades sociais, investindo-se esforços no desenvolvimento individual dos alunos, por meio de uma Educação centrada nos interesses das crianças, de tradição escolanovista, na qual se considere "[...] as necessidades, 
as possibilidades e os interesses dos estudantes, assim como suas identidades linguísticas, étnicas e culturais" (BRASIL, 2018, p. 15). Identificamos uma relação de complementaridade entre os documentos que se constituem nos marcos legais da BNCC e, ao mesmo tempo, uma reinterpretação das legislações anteriores, de modo a responder às demandas de uma Educação escolar mais controlada pelo Estado, diversamente do que se propalava na sociedade, quando da promulgação da Constituição Federal, da LDBEN e dos PCN:

[...] se identificam na comunhão de princípios e valores que, [...] orientam a LDB e as DCN, [...] reconhecem que a educação tem um compromisso com a formação e o desenvolvimento humano global, em suas dimensões intelectual, física, afetiva, social, ética, moral e simbólica (BRASIL, 2018, p. 16).

Embora a BNCC tenha sido produzida no âmbito de um simulacro de debate democrático, na forma de consultas pela internet - sem ampla discussão na sociedade e sem considerar as manifestações provenientes da sociedade civil organizada, estabelece diretrizes de produção do consenso, como o envolvimento das famílias, da comunidade e dos professores, com o apoio dos estados federados. Nesse sentido, ele aponta, numa perspectiva progressiva, que as decisões devem resultar de processos participativos da família e da comunidade, bem como do efetivo funcionamento do regime de colaboração, que foi legitimado pelo pacto interfederativo, por meio da Lei $\mathrm{n}^{\circ} 13.005 / 2014$, e estabelece uma política para a adesão dos professores sob a mediação da política de formação continuada.

No entanto, pode-se compreender como contraditória a apresentação, como instrumento de construção do consenso em torno da BNCC, a ação protagonista da União na produção do material didático e na avaliação da implantação da política, ao "promover e coordenar ações e políticas em âmbito federal, estadual e municipal, referentes à avaliação, à elaboração de materiais pedagógicos e aos critérios para a oferta de infraestrutura adequada para o pleno desenvolvimento da Educação" (BRASIL, 2018, p. 21).

Parece-nos que o consenso não deverá surgir da participação mais ampla nas deliberações, mas se limita à participação das escolas apenas na utilização e na opinião sobre esses materiais, bem como na aplicação de avaliações, para coleta de dados, de modo que,

[...] para este novo ciclo observar se ao longo do tempo as médias descem ou sobem e não se as formas de organização das práticas 
pedagógicas das escolas evoluem em direção a concepções avançadas de educação e de participação social da juventude (FREITAS, 2014, p. 1088).

O processo de elaboração e de implantação da BNCC deu-se de modo que, no âmbito da aparência, garantisse uma discussão democrática e consensual; porém, desde sua apresentação, em 2015, a participação da comunidade foi controlada pelo governo, por meio da coleta de opiniões pela internet. Após isto, todas as providências para a garantia da implantação dessa política têm sido centralizadas pela União, para que se garanta que esteja presente como diretriz para a gestão escolar o material didático e a formação de profissionais, bem como a avaliação institucional, que será tanto mais positiva quanto mais fiéis forem às diretrizes propostas. A produção do consenso em torno da $\mathrm{BNCC}$ se dá pela via da vinculação entre sua aplicação e a avaliação das instituições escolares, consequentemente, a destinação de verbas e a pesquisa, pois o MEC deverá promover

[...] o fomento a inovações e a disseminação de casos de sucesso; o apoio a experiências curriculares inovadoras; a criação de oportunidades de acesso a conhecimentos e experiências de outros países; e, ainda, o fomento de estudos e pesquisas sobre currículos e temas afins (BRASIL, 2018, p. 21).

Esse fomento para a disseminação de casos de sucesso e o apoio a experiências curriculares inovadoras pode aumentar ainda mais o fosso existente entre as escolas de maiores e as de menores índices nos testes, de maneira que as "melhores" e as mais "inovadoras" serão apoiadas e servirão de modelo.

\section{Considerações finais}

Para além do caráter minimalista dos conteúdos e a homogeneização das práticas pedagógicas, evidencia-se uma metodologia de democratização da decisão política sobre o currículo nacional em que a sociedade civil tem uma função consultiva e fiscalizadora, pois as escolas mais mal avaliadas e, consequentemente, menos escolhidas pelos pais e pelos alunos, serão consideradas menos produtivas. As funções deliberativa, normativa, avaliativa, fiscalizadora e de fomento ainda se centralizam no governo federal e as funções executivas ficam a cargo das instituições escolares, com os recursos que thes forem disponibilizados sob os auspícios de cada governo.

A compreensão sobre "o que deve ser ensinado", "o quanto deve ser ensinado" e a forma como deve se dar o Ensino é influenciada pelos contextos sociais e 
históricos, dando materialidade à função social da escola, sempre em disputa entre as classes fundamentais, constituindo um campo de conflito pela hegemonia sobre o conhecimento e sobre a própria sociedade.

Embora a BNCC proclame os princípios da objetividade, da justiça distributiva, dos direitos de aprendizagem e da democracia, a busca pela qualidade educacional se fundamenta no eficientismo, que reduz o direito à Educação à concessão de serviços educacionais em suas dimensões prático-instrutivas, vinculando a qualidade aos resultados das avaliações externas.

O processo educativo imposto na $\mathrm{BNCC}$ visa à aquisição de competências e habilidades, impõe uma relação entre currículo e avaliação por resultados e se alinha às políticas educacionais neoliberais em que a Educação se reduz a direitos de aprendizagem mínimos, oferta de serviços educacionais básicos pelo Estado e estimulação para que os indivíduos busquem a autoescolarização, uma contradição em termos.

A centralidade no desenvolvimento de "competências gerais", no documento, remete-nos à influência que o modelo recebe da racionalidade tyleriana e tecnicista reeditada, como decorrência da adesão ao modismo das pedagogias tecnicista desde os anos 1970, da pressão decorrente das "parcerias feitas entre o país e os Estados Unidos, como os Acordos MEC-USAID" (SILVA, 2008, p. 56). Acrescemos que desde aquela época até hoje, há uma pressão do mercado pela contração dos sistemas públicos de Ensino, simultânea à expansão da rede privada (CUNHA, 2007), bem como pelo controle, pelo Estado burguês sobre os conteúdos da formação dos trabalhadores. A noção de competência mencionada desde as políticas públicas de formação inicial e continuada de professores, na LDBEN, nas diretrizes curriculares na Educação Básica prescreve os comportamentos a serem modificados e avaliados nos alunos, como "características gerais da ação humana: saber-fazer, saber-ser, saber-aprender, cooperar e viver". Convenientemente para o campo empresarial, "as relações entre trabalho e Educação tenderiam, assim, a ser orientadas pela noção de competência, e não mais pela ideia de qualificação" (SILVA, 2008, p. 79).

Assim como na produção toyotista a demanda impõe o ritmo ao processo de produção; na escola, os critérios da avaliação por resultados instituem práticas pedagógicas e conteúdos privilegiados no Ensino, no qual tudo se organiza para uma avaliação auspiciosa. Esse estreitamento entre currículo e avaliação é justificado pela ideia de que, a partir de critérios previamente estruturados, é possível facilitar a objetividade e romper com a subjetividade do processo avaliativo, o que gera um caráter receituário do que deve ser ensinado. 
Entretanto, esse modelo não é capaz de avaliar os aprendizados cuja fixação ultrapassa o momento da avaliação, bem como não apreende as transformações na consciência, que exigem um desenvolvimento psíquico dos alunos.

A BNCC aproxima-se de perspectivas das teorias-currículo que são produtos do neoliberalismo, tais como a pedagogia das competências, o multiculturalismo, que são focos dos estudos da perspectiva pós-crítica do currículo.

Concluímos que o documento analisado impõe a formação para a empregabilidade em detrimento da formação integral, geral, emancipadora e rica de potencialidades para o desenvolvimento das funções psíquicas na escola e cujos elementos não são sequer mencionados no documento, constituindo, antes, uma política de padronização dos conteúdos de uma formação mínima e de introdução de metodologias, sob influência da organização do trabalho toyotista, do que uma proposta de Educação crítica, como forma de emancipação dos sujeitos da aprendizagem.

A BNCC e as políticas relacionadas ao documento implicam em mudanças significativas na escola, tais como: estreitamento curricular; projeção de um currículo para moldar a formação do trabalhador; reforço das desigualdades por meio das avaliações; ameaça à autonomia do professor (controle do seu trabalho, visto como mero executor de tarefas); formação dos professores de acordo com a "lógica" hegemônica; abertura para privatizações (produção de material didático por empresas privadas); responsabilização.

As proposições da BNCC articulam-se organicamente como estratégias de reprodução do modo de produção capitalista, buscando atender à demanda da força de trabalho polivalente, multifuncional, resiliente e colaborativa no processo de expropriação de mais-valia, ao mesmo tempo em que se institui como dispositivo legal para o controle sobre o que o professor ensina, a partir de teorizações superadas e criticadas nas décadas precedentes, pelo seu caráter restritivo e empobrecedor da formação humana das funções psíquicas por meio da Educação escolar. Devido à objetividade das disputas interclassistas e à subjetividade envolvida nas escolhas sobre o que se ensina e se aprende, no limite, o controle se revela intangível. 


\title{
A common school base: analysing the National Curricular Common Base educational Project
}

\begin{abstract}
The aim of this article was to analyse the educational project proposed as the basis of the National Curricular Common Base (NCCB). To do this, a qualitative, documental research was carried out of the final version of NCCB, April 2017, approved on December 20, by the National Education Council. We observed that the NCCB is based on an educational training project for employability, using centrality of competencies, based on a directed Teaching model, prescriptive and linked to an efficiency evaluation model, inspired by behavioural theories. We concluded that NCCB proposals are removed from an educational Project aimed at a critical and emancipatory formation, because they propose to train for the work according to neoliberal demands.
\end{abstract}

Keywords: National Curricular Common Base. Curriculum Conceptions. Neoliberal Educational Project.

\section{Una base común en la escuela: análisis del proyecto educativo de la Base Nacional Común Curricular}

\section{Resumen}

El propósito de este artículo fue analizar el proyecto educativo propuesto como fundamento de la Base Nacional Común Curricular. Realizamos una investigación cualitativa y documental de la versión final de BNCC, de abril de 2017, homologada el 20 de diciembre de 2017 por el Consejo Nacional de Educación. Identificamos que BNCC se fundamenta en un proyecto educativo de formación para la empleabilidad, con la centralidad de las competencias, a partir de un modelo de Enseñanza direccionada, prescriptiva y vinculada a un modelo de evaluación eficiente, inspirado en las teorías comportamentales e concluimos que las proposiciones de BNCC se distancian de un proyecto educativo que apunta a una formación crítica y emancipatoria, pues visa formar para el trabajo de acuerdo con las demandas neoliberales.

Palabras clave: Base Nacional Común Curricular. Concepciones de Currículo. Proyecto Educativo Neoliberal. 


\section{Referências}

BLOOM, B. S. et al. Taxonomia de objetivos educacionais. Porto Alegre: Globo, 1973.

BRASIL. Constituição da República Federativa do Brasil de 1988. Diário Oficial da União, Brasília, DF, 6 out. 1988.

BRASIL. Lei no 13.005, de 25 de junho de 2014. Aprova o Plano Nacional de Educação - PNE e dá outras providências. Diário Oficial da União, Brasília, DF, 26 jun. 2014.

BRASIL. Base Nacional Comum Curricular (BNCC): educação é a base. Brasília, DF: MEC/CONSED/UNDIME, 2018. Disponível em: http://basenacionalcomum. mec.gov.br/images/BNCC_publicacao.pdf. Acesso em: 23 mar. 2018.

BULHÕES, L. F. S. S. Crítica ao conceito de Necessidades Básicas de Aprendizagem (NEBA) a partir da categoria marxiana de necessidades humanas. Tese (Doutorado em Educação Escolar) - Faculdade de Ciências e Letras, Universidade Estadual Paulista “Júlio de Mesquita Filho", 2016.

CARVALHO, F. A.; POLIZEL, A. L.; MAIO, R. Uma escola sem partido: dicursividade, currículos e movimentos sociais. Semina: Ciências Sociais e Humanas, Londrina, v. 37, n. 2, p. 193-210, jul./dez. 2016. https://doi.org/10.5433/1679-0383.2016v37n2p193

CUNHA, L. A. O desenvolvimento meandroso da educação brasileira entre o estado e o mercado. Educação \& Sociedade, Campinas, v. 28, n. 100, p. 809-829, out. 2007. https://doi.org/10.1590/S0101-73302007000300009

DUARTE, N. O debate contemporâneo das teorias pedagógicas. In: MARTINS, L. M.; DUARTE, N. (orgs.). Formação de professores: limites contemporâneos e alternativas necessárias. São Paulo: Editora UNESP: Cultura Acadêmica, 2010.

FERRRAZ, A. P. C. M.; BELHOT, R. V. Taxonomia de Bloom: revisão teórica e apresentação das adequações do instrumento para definição de objetivos instrucionais. Gestão \& Produção, São Carlos, v. 17, n. 2, p. 421-431, 2010. https://doi.org/10.1590/S0104-530X2010000200015

FRANGELLA, R. C. P; MENDES, J. C. B. "O que é o bom resultado?" Indagando o sentido da avaliação e suas articulações curriculares. Ensaio: Avaliação e Políticas Públicas em Educação, Rio de Janeiro, v. 26, n. 99, p. 296-315, abr.jun., 2018. https://doi.org/10.1590/s0104-40362018002600982 
FREITAS, L. C. Os reformadores empresariais da educação e a disputa pelo controle do processo pedagógico na escola. Educação \& Sociedade, Campinas, v. 35, nº 129 , p. 1085-1114, out./dez. 2014. https://doi.org/10.1590/ES0101-73302014143817

GRAMSCI, A. Os intelectuais e a organização da cultura. 4. ed. Rio de Janeiro: Civilização Brasileira, 1982.

LOPES, A. C.; MACEDO, E. Teorias de currículo. São Paulo: Cortez, 2011.

MACEDO, E. Currículo e conhecimento: aproximações entre educação e ensino. Cadernos de Pesquisa, São Paulo, v.42, n. 147, p.716-757, dez. 2012. https://doi.org/10.1590/S0100-15742012000300004

MACEDO, E. As demandas conservadoras do movimento escola sem partido e a Base Nacional Curricular Comum. Educação \& Sociedade, Campinas, v.38, n.139, p. 507-524, abr.jun, 2017. https://doi.org/10.1590/es0101-73302017177445

MARX, K. O capital: crítica da economia política. Rio de Janeiro: Civilização Brasileira, 1998. Livro I, v. I.

ORGANIZAÇÕES DAS NAÇÕES UNIDAS PARA A EDUCAÇÃO, CIÊNCIA E CULTURA - UNESCO. Declaração Mundial sobre Educação Para Todos (Conferência de Jomtien). Tailândia: Unesco, 1990. Disponível em: https://www.unicef.org/brazil/declaracao-mundial-sobre-educacao-paratodos-conferencia-de-jomtien-1990. Acesso em: 27 jul. 2018.

SANTOS, L. L. Administrando o currículo ou os efeitos da gestão no desenvolvimento curricular. Educação em Revista, Belo Horizonte, v. 33, e166063, 2017. https://doi.org/10.1590/0102-4698166

SANTOS, L. L. C. P.; DINIZ-PEREIRA, J. E. E. Tentativas de padronização do currículo e da formação de professores no Brasil. Cadernos Cedes, Campinas, v. 36, n. 100, p. 281-300, set./dez, 2016. https://doi.org/10.1590/cc0101-32622016171703

SAVIANI, D. Educação escolar, currículo e sociedade: o problema da Base Nacional Comum Curricular. Movimento- Revista de Educação, Rio de Janeiro, v. 3, n. 4, p. 54-84, jan./ago, 2016. https://doi.org/10.22409/mov.v0i4

SILVA, M. R. Currículo e competências: a formação administrada. São Paulo: Cortez, 2008

SILVA, T. T. Documentos de identidade: uma introdução às teorias do currículo. 3. ed. Belo Horizonte: Autêntica, 2013. 


\section{Informações sobre as autoras}

Fabiana Alvarenga Filipe: Mestre em Educação pela Universidade Estadual Paulista "Júlio de Mesquita Filho", campus Rio Claro, São Paulo. Doutoranda pelo Programa de Pós-Graduação em Educação na área de Políticas Públicas da mesma universidade. Contato: fabiana alvarenga@yahoo.com.br

iD https://orcid.org/0000-0001-8100-2320

Dayane dos Santos Silva: Mestre em Educação pela Universidade Estadual Paulista "Júlio de Mesquita Filho", campus Rio Claro, São Paulo. Doutoranda pelo Programa de Pós-Graduação em Educação na área de Educação Ambiental da mesma universidade. Contato: dayanedosssilva@gmail.com

iD https://orcid.org/0000-0002-1073-5495

Áurea de Carvalho Costa: Doutora em Educação pela Universidade Estadual de Campinas, São Paulo. Pós-Doutorado em Trabalho e Educação pela Universidade Estadual Paulista "Júlio de Mesquita Filho", campus Rio Claro, São Paulo. Professora da mesma universidade. Contato: aurea.costa@unesp.br

iD https://orcid.org/0000-0003-2695-4235 